\section{Scientists are playing their part in power saving}

\section{John Hall}

IN Britain the arrival of the three-day working week, complete with regulations restricting the use of power, raises the spectre of an earlier age of science. Might one expect, without undue romanticism, to be conducting enquiries by the glow of a tallow candle? The speculation, as it happens, turns out to be as inaccurate as it is morbid. By and large, research goes ahead under neon lights, albeit fewer of them, and with power supplies reduced in some cases to $60 \%$ of normal and in others not at all.

The Statutory Order restricting the use of electricity offers three channels of escape (at least) which ensure the survival of research programmes whose existence depends on supplies of power. In the first place, work which is taking place at a university is in the clear because of the exemption from cuts allowed to places of education. A further clause in the order allows the operation of apparatus "which has been continuously in use for purposes of research until such time as the operation of the said apparatus can be discontinued without causing loss or damage"a flexible looking provision, since the order does not actually specify that the loss should be of materials rather than of information. And additionally, the regular supply of power is allowed for the operation of any computer "and any other equipment necessary for the proper functioning thereof". As a last resort a laboratory can make a special plea to regional officers of the Department of Trade and Industry, who have been instructed to avoid "rigid attitudes" in dealing with such applications.

At Jodrell Bank, in spite of a power reduction of $75 \%$, the radio telescopes are still functioning twenty-four hours a day for seven days a week. In fact, says Professor Sir Bernard Lovell, the telescopes use less power than the cooker in the station's canteen. The total load for the entire establishment at present is only $35 \mathrm{~kW}$ and even if the regulations were changed in the event of a worsening power situation, Jodrell Bank's own generator could fill the gap for several weeks. The Appleton Laboratory, formerly the Radio and Space Research Station, at Slough is working a five-day week with only three days of power and has had to delay work on certain projects.

University College, London, which hopes to take its electricity for the full five days, but at a voluntarily reduced level of $60 \%$ of normal consumption, also has certain difficulties. As it happens, the Faculty of Medical Sciences has no animal experiments in train and since its other projects were part of teaching programmes, none of its work has been affected. The Department of Chemical Engineering, with a pilot plant which attempts to translate laboratory biochemistry into industrial process design, is, however, a heavy user of power. Large scale fermentation and isolation runs carried out under industrial conditions, can use motor power amounting to 80 horse power.

Dr Peter Dunnill says the department can scarcely afford to have its $£ 0.25$ million worth of equipment standing idle but at the same time it is not really feasible to do biological research on a three-day week or at reduced power. Rather, the department will try to take its $60 \%$ of power at the normal rate for, say, one full week in every four.

The Royal Aircraft Establishment at Farnborough, reduced to $65 \%$ consumption, spread over five days a week, has elected, stoically, to "make do and mend". Computer work and continous process research is unaffected but testing programmes, including work for Concorde, has to be done "as and when we can manage it", said a spokesman. The nearby National Gas Turbine Establishment is working on the same basis.

The Atomic Energy Authority's research establishments at Culham and Harwell are surviving by using $65 \%$ of their November daily average requirement, as are the Dounreay Fast Reactor and the Winfrith Steam Generating Heavy Water Reactor-in spite of the fact that they generate $114 \mathrm{MW}$ between them. Apparently it is considered unethical to plug in your lighting and heating at source.

\section{Naples \\ at the crossroads}

THARe is great international interest in the establishment of new conditions at the Naples Zoological Station. The station fulfils for marine biology (along with a number of other stations such as Monaco, Plymouth and Woods Hole) similar functions to those that large accelerators do for nuclear physics. In addition to having a staff of its own, the station is capable of housing large numbers of international visitors. It is not alone among Italian scientific institutions in having recently fallen on hard times as a result of dissatisfaction with the administration among its resident workers.

The Italian government has reacted to discontent within the station by installing a Commissario whilst the administration was overhauled. A new set of statutes has been provided and the financial basis for the station is much sounder. Italy will provide about $£ 400,000$ annually and any country which contributes more than $£ 40,000$ annually will be entitled to a seat on the new Administrative Council. It is hoped that Britain will have a seat.

Prospects are much "brighter for a settled future but the remaining question is whether the science will be stimulating. This hangs on two issues-who will be the new director and what sort of programmes will he institute? The permanent staff have gone to unusual lengths to ensure that the community is well informed of the needs of the station; a recent advertisement in Nature invited suggestions for the development of the institution and by inference nominations for the directorship. It is important at this juncture that, even though the station is understaffed, the decision not be made in a hurry - certainly not until the council has had time to feel its feet.

\section{PSAC reports from the grave}

\section{Colin Norman, Washington}

The President's Science Advisory Committee (PSAC) has posthumously complained about the federal government's methods of regulating public exposure to chemicals in the United States. It has also added its ghostly voice to the chorus of opposition to one of the most controversial, and certainly the most effective, pieces of consumer legislation on the lawbooks - the so-callcd Delaney Amendment which seeks to ban the addition to food of any substance which has been found to cause cancer in animals.

Although PSAC was a victim of President Nixon's post-clection massacre of the science advisory apparatus in the United States (the massacre which scrapped the Office of Science and Technology and banished scientists from the White House), its reports continue to surface in Washington as reminders of a past age in science policy making. This latest PSAC report (Chemicals and Health, US Government Printing Office, \$2.75), was released last week by Dr H. Guyford Stever, Director of the National Science Foundation, and inheritor of most of the responsibilities which werc assigned to the Office of Science and Technology. Stever described the report last week as a "broad, yet intensive, examination of the processes of Federal regulation of chemicals ... performed in the name of health".

Prepared by a committee which met under the chairmunship of Dr John W. Tukey, Professor of Statistics at Princeton, the report argues for more flexibil- 